in partnership with management and other agencies, for the delivery of a safe national mental health service."

In response to an inquiry from $\mathrm{Dr} J o h n$ Henderson, Dr Hollander suggested that the resolution should apply to the Department of Health in England and Wales only at this stage.

Dr Martin Deahl proposed a revised resolution, copies of which were made available, which embodied most of the points in the original resolution, and addressed several additional points. These included concern about the lack of consultation and disregard by Health Authorities and purchasers for professional advice, concern about the increasing level of bureaucracy and introduction of guidelines, the effectiveness of which had not been tested, the scapegoating of individual psychiatrists, and the effects of manpower planning on the training of staff.

Dr Deahl's resolution was seconded by $\mathrm{Dr}$ Trevor Turner.

The meeting considered in turn each of the proposed amendments to the resolution proposed by $\mathrm{Dr}$ Hollander and seconded by Professor Hirsch.
The inclusion of the phrase '24 hour nursed beds' in place of 'cost-effective havens' was supported by a majority of at least two-thirds of the Members of the College present and voting at the meeting.

The inclusion of the Health Advisory Service as an example of an inspectorate to ensure that there are appropriately trained staff in community-based developments for the mentally ill was not supported.

The addition of a final paragraph stating 'and that every district should be required to produce a plan for a comprehensive spectrum of care to be implemented within three years', was supported by a majority of at least two-thirds of the Members of the College present and voting at the meeting.

The resolution proposed by Dr Hollander, with the inclusion of the above amendments, was carried.

The amended resolution proposed by Dr Deahl was not supported.

Copies of the Resolution on care in the community are available from the College Secretary on written request.

\title{
Election and introduction of Honorary Fellows
}

The following were unanimously welcomed to the Honorary Fellowship.

\section{Duchess of Kent (introduced by Dame Fiona Caldicott)}

Her Royal Highness The Duchess of Kent was born Katharine Lucy Mary Worsley and grew up in Yorkshire. She was educated in Yorkshire and Norfolk and subsequently studied music in Oxford. She worked in a children's home in York and taught at a kindergarten in London. She married His Royal Highness The Duke of Kent in 1961 and has two sons and a daughter, two grandsons and two granddaughters.

Her Royal Highness is Deputy Colonel in Chief of the Adjutant General's Corps., Deputy Colonel in Chief of the Royal Dragoon Guards, and Colonel in Chief of The Prince of Wales Own Regiment of Yorkshire. She is Chancellor of the University of Leeds, President of the Royal Northern College of Music, and Patron of the Christie
Hospital in Manchester, the Yehudi Menuhin School and a large number of charities including SCOPE, Age Concern, Cancer Relief, the Samaritans and the Arthritis and Rheumatism Council. She is also President of the British Legion Village in Kent.

She has the Honorary Freedom of four of the Ancient City Companies, the Worshipful Companies of Cloth Workers, Dyers, Glazlers and the Coach Makers and Coach Harness Makers.

Her Royal Highness became Patron of the United Kingdom Committee for UNICEF in 1971 and in this capacity has visited field projects in Goa and Tanzania.

The Duchess was created a Dame of the Grand Cross of the Royal Victorian Order (GCVO) in 1977 and was awarded the Honorary Freedom of the City of York in 1989. She is an accomplished pianist and sings regularly as a member of the Bach Choir.

Her Royal Highness is being honoured today for her involvement with the Samaritans. She agreed to become their Royal Patron making the condi- 
tion that she trained as a Samaritan Volunteer. It will be well known to this audience that that training is rigorous. Her Royal Highness then spent a period of time undertaking duties as a Samaritan Volunteer although it has not been possible for her to maintain this particular involvement owing to the great demands made on her from many other directions. Nevertheless her training and experience as a Samaritan have ensured that she remains close to the essence of the work of that organisation.

The Duchess undertakes a number of functions for the Samaritans each year and from time to time addresses the annual conference. At such occasions it is particularly significant that she is able to speak to Samaritan Volunteers from the perspective of her own experience. The Duchess of Kent has always been and continues to be an inspiration for the work of the Samaritans. She takes a keen interest in the development of the service that Samaritans provide to the community and it was a great honour for the Samaritans when she formally launched their new One Number Service in November, 1995.

The Duchess has talked very movingly about what it is like as an individual Samaritan listening to suicidal talk down the telephone. She has been asked "How do you respond?". "Simply in the most human way you can by trying to put yourself in that person's position. I don't believe there is anyone in the world who hasn't suffered something. All of us have had some cross to bear and it is through these experiences one learns empathy and compassion". She has pointed out that the listening Samaritan may provide the first occasion when someone has really listened to the suffering individual and helped them to find something positive in their lives to build on.

It is clear from what the Duchess herself has said of the work of the organisation and the way in which both her patronage and her work for the Samaritans are regarded within and beyond the organisation that she has acquired deep understanding of the desperate problems which beset those who tentatively approach the Samaritans and for whom the first response that they receive is all important.

Many of these individuals are mentally 111 and the Royal College of Psychiatrists wishes to give Her Royal Highness the Duchess of Kent its highest honour, an Honorary Fellowship, in recognition of the contribution which she has made to their care.

\section{Lady Ann Parkinson (introduced by Professor John Strang)}

I am delighted to have an opportunity today to introduce Lady Parkinson to you - not only because it is a privilege and a pleasure to be introducing someone whom I regard as a respected colleague and friend, but also because it gives me a chance to say a special 'thank you' to Ann Parkinson for all her splendid work over so many years.

Ann Parkinson has contributed so much to altering public opinions with regard to the addictions, and has spoken out forcefully and poignantly about the pervastve nature of drug and alcohol problems within all sections of society today, about the need to search for new improved understanding of the origins of, and influences upon, substance misuse, and about the urgent need to develop more effective prevention and treatment strategles. And, beyond the rhetoric, Ann has been a determined fighter to force the reappraisal, to stimulate the more determined research endeavour, to test out the new preventive or treatment approach - and to refuse to take 'no' as an answer when seeking support for some new project.

Ann certainly brings a sharpness to any debate in the field of substance misuse - whether drawing on her wide and varied business experience. her training during her BSc Honours degree in sociology, her husband Lord Parkinson's political career, or through her own personal experiences and insights. And, throughout such debate, one particular aspect of Ann comes through so powerfully - the warmth and humanity, the essential understanding of individual and family plight, and the desperate need for more serious attention to this oft-ignored and oft-neglected part of the mental health field.

In the last minute or two. I would like to pull out just some of Lady Parkinson's important contributions to the Addictions field. I will not focus on her work as Chairman of Hertfordshire Alcohol Advisory Service, nor even her work as Chairman of the London Alcohol Forum. Rather, I will talk about just two areas.

The first of these two areas is her work as Chair of 'Drinkline', the national alcohol telephone helpline. From a germ of an idea a number of years ago, Drinkline has now grown into a formidable venture, offering direct access to information and the opportunity to discuss one's alcohol problem (or the drinking behaviour of a loved one) on a fully anonymous basis to anyone with access to a telephone. And Ann has been there, actively involved, at all stages of the project - from discussions about how the telephone teams should be coordinated, to debate about audit of the venture, to the pressure group to secure new funding or continuity of funding. And, as an indication of how successful she has been, the Department of Health last year launched an equivalent 'drugs' project, DrugsLine.

The second and final area to which I wish to refer is her work with the charity Action on 
Addiction (initially being centrally involved in its conception and birth 9 years ago, and particularly in recent years during which she has been Chairman of Action on Addiction). Her vision of Action on Addiction was that it would stimulate new activity in prevention, treatment, research and training in the addictions. On behalf of colleagues at the National Addiction Centre at the Maudsley and Institute of Psychiatry, I can attest to Ann Parkinson's outstanding commitment and energy. Over the nine years, the support of Action on Addiction has been so vital to various of our endeavours - our new MSc course, our new academic base (the Addiction Sciences Building), our prevention and early intervention project, new molecular genetic search for markers of vulnerability. A particularly important recent further achievement was the successful negotiation with the University of London to create the first endowed Chair in the psychiatry of the addictions to lead the activity at the National Addiction Centre. Indeed I am privileged to be speaking to you today as the first post-holder in this new Chair.

And so it is with great pleasure that I introduce the Lady Parkinson to you today as an Honorary Fellow; and that I say to you, Ann, on behalf of my colleagues, welcome to the Royal College of Psychiatrists.

\section{Professor Arthur Hamilton Crisp (introduced by Professor Hubert Lacey)}

To psychiatry's inestimable gain, Arthur Crisp was deflected from his first career choice of engineering when he was hospitalised following an accident while playing rugby. This early recognition that life-events can govern the expression of disease led to the study of medicine and subsequently psychiatry. Although offered a place at the Maudsley, he chose instead to train at St George's. I have never asked him if he regrets his decision but feel, somehow, that I know his answer!

Arthur Crisp is one of the most distinguished psychiatrists of his generation. He is Professor Emeritus of the University of London and was Vice-President of our College. Until his retirement, he was Professor and Chairman of the Department of Psychiatry at St George's Hospital Medical School.

There are many aspects of Arthur which I would like to touch on: his courtesy and humour, his commitment to clinical practice and to the clinical sciences, and the emphasis he places on clinical research. Arthur is a family man and a shy man. Most find him predominantly private, but having a deep and well thought-out personal philosophy which drives his life at work and at play. He can fight his corner without rancour and has been a powerful advocate for psychiatry as it has found its place in modern medical practice.

A doctor, Arthur once said, is primarily a teacher. Over the last 30 years, Arthur's name has been associated with undergraduate and postgraduate medical education. It was he who integrated the examination of psychiatry into the final MBBS Examination of the University of London. This led to his election as Dean of the Faculty of Medicine. During his stewardship of the Education Committee of the General Medical Council, the medical curriculum acquired a broader and more relevant base. There was a firmer recognition that medicine has its roots in sociology and psychology, as well as physiology and anatomy. Arthur united his colleagues in a recognition that the modern doctor needs to draw deeply on a holistic understanding of the patient encompassing body, mind and society; that in a high-tech world, a doctor must retain core clinical skills and remain comfortable in an empathic relationship with a patient. Arthur created an undergraduate psychiatric education programme at St George's which sparkled and was quite embarrassingly popular with students. It was reflected in the large percentage of his students who went on to choose psychiatry as a career: a testament to his clinical example.

The psychiatric postgraduate training which he established in the old South West Thames Region was a model of its kind. It emphasised the acquisition of a broad range of knowledge, skills and attitudes based on an eclectic mix of general and speciality experience. Not for Arthur the dogmatic, limited preoccupations of sectarian psychiatry. For him behavioural, psychodynamic and pharmacological approaches were equally relevant when based on a diagnostic interview which attempts to answer the question 'why', as well as 'how'. The humanistic St George's approach, developed by Arthur, in which psychiatrists must carefully define the social, biological and psychological features of a patient and be able to harness them in treatment, using pharmacology and a broad spectrum of psychotherapies, had a profound influence on a generation of psychiatrists. He took this work to The European Union when, as Chairman of The Committee of Medical Training, he laid down plans for Europe-wide postgraduate training which has recently seen fruition in the United Kingdom as our specialist training grades.

To Arthur, research is dominant. He has researched even his hobbies, one of which was a study of the River Wandle, a river which goes through the St George's catchment area. On one occasion he wished to photograph the river at dawn as it flows close to Springfield Psychiatric Hospital. The best view could be got from the roof above the locked ward. Unfortunately, the door to the roof locked behind Arthur, leaving him 
stranded. No-one was around, save the milkman delivering to the hospital. Arthur called to him that he must be let out! The milkman nodded wisely. Arthur shouted that he was Professor of Psychiatry! The milkman nodded even more wisely. ....

Arthur's research has had an unashamedly clinical focus anchored in psychosomatic medicine. I well remember a thrilling lecture he gave in the early seventies in which he described the interplay of mind, behaviour and endocrinology: a lecture that was to completely change my own career plans.

Arthur has explored the relationship between sleep and nutrition, investigated migraine and the psychosomatic aspects of myocardial infarction, irritable bowel and even writer's cramp! He conducted experimental studies of psychotherapeutic processes, overcoming the formidable difficulties of conducting a controlled evaluation of interpretive psychotherapy.

It is, however, in the field of anorexia nervosa that Arthur's international reputation rests. He defined anorexia in its modern-day terms. He determined its psychopathology, its aetiology and pathogenesis. His statement that the core pathognomonic feature of anorexia is a phobic avoidance of normal body-weight, has stood the test of time. His treatment programme for anorexia is the international gold standard.

Arthur Crisp has achieved high office and rightly so. He has been one of psychiatry's great pioneer educationalists and certainly the one who has brought psychiatry and psychological ideas into the mainstream of medicine. $\mathrm{He}$ is an international authority in his research field and diagnostic criteria for anorexia originally proposed by him have been incorporated into the two main systems of classification.

It is therefore with delight, satisfaction and pride that I ask you, Madam President and our colleagues, to welcome Arthur Crisp, Professor Emeritus to St George's Hospital Medical School, as an Honorary Fellow of our College.

\section{Sir Leslie Turnberg (introduced by Professor Sir David Goldberg)}

Leslie Turnberg and I were appointed professors at the same medical school in the same year, although we are both currently serving time in London. Unlike me, in his case, the prodigal son is likely to return. He has also been my President; my Dean; my Regional Director of R\&D and my doctor.

He is a quintessential Manchester man: a product of a local grammar school and Manchester University; after housejobs in Manchester he got his first job at the prestigious MRI in 1960. In what was clearly an aberration he then spent 4 years as a Registrar at $\mathrm{UCH}$; later working as a lecturer to Sheila Sherlock; he then got his BTA by going to the University of Texas as a Research Fellow in Gastroenterology.

The die was now cast; he returned to Manchester as a Senior Lecturer in Gastroenterology in 1968; and became professor in 1973. He has had visiting professorships in four exotic foreign locations, as well as in less exotic, but distinguished. British ones. Over the years after his return to Manchester, Les turned out a series of key papers on ionic transport in the small gut, on Crohn's disease and on virtually every apsect of diarrhoea.

He was therefore my natural choice of doctor when I returned from a stint in Burma and collapsed after having developed a peculiarly intractable complaint that seemed to fit well with some of his recent papers. Les looked after me wonderfully, and all too thoroughly. I was eventually admitted to his Unit for 3 days, during which time I experienced investigations too horrible to repeat before a mixed audience. I can have no secrets from a man who has had a tube looking into - what felt like - my appendix. Memory falters at which end of my intestinal tract the tube started out from. On the evening of my discharge Les's SHO visited me for the first time, and took a history from me. It was faultless: at the end, he even recapitulated the main points of my history, and sought my agreement. "Where did you learn to do that?" I cried. "In the department of psychiatry", he answered proudly. Even then, you see, medicine and psychiatry worked well together. Unfortunately we had neglected to tell him when to take the history.

However, Les managed to cure me of my obscure tropical disease - although characteristically he made little of his accomplishment. He told me to take tetracycline for a year, and to come back when the course was finished. This is, of course, an admirable way of handling difficult patients; which I have since used myself on occasion - although so far, not with tetracycline.

He became Dean of the Medical School in 1986. and made a great success of this. He installed the first fax machine; and charged users in other departments $10 p$ a sheet to send, $5 p$ a sheet to receive: this revolutionised finances in the Dean's Office. Indeed, his flair with the fax machine encourged me to forgive him for his Luddite views about computers. Leslie asked me to organise research electives for our medical students, and I asked for the modest sum of $£ 40$ to enable me to buy a second hand $\mathrm{BBC}$ computer to run the database for this project. Although he granted me this sum, he looked rather hurt as he did so, and remarked that cards in a shoebox had always served him well on these occasions.

During this time he sometimes had to visit the Medical School with his elderly mother, and 
would leave her parked outside the Church of the Sacred Heart, which happened to be next door. This, combined with the fact that he was now the Dean, made his mother doubt that his appointment was wholly secular.

His brief but promising time as our Regional Director of $R \& D$ was interrupted by his election to the presidency of the College of Physicians. In Manchester, this was the medical equivalent of United winning the Cup; and doctors across the country soon felt the same way. As PRCP he has made the College more responsive to the Fellowship by regional visits; appointed advisers round the country in each speciality; improved relationships between Colleges, culminating in an Academy of Royal Colleges which our own president has recently chaired.

He has campaigned to set up a Specialist Training Authority which gives statutory responsibility to the Colleges for postgraduate training; and has finally both started and hopes to finish a new building extension to the College. Colleagues at the College tell me that he is absolutely marvellous to work with; full of energy and good ideas: completely unpompous and a breath of fresh air. I can attest that his after dinner speeches at the College are both witty and interesting.

In the course of a very full professional life Les has trained many young doctors in research methods in gastroenterology, and over 130 refereed publications mention large numbers of those who are now established as gastroenterologists. His contact with his team has necessarlly been somewhat more difficult since his time as PRCP. During a recent meeting in Belfast, Les asked a question after a paper on oesophageal function; only to be told that the work had been done, and in his own department. This did not put Les out at all: he stoutly denied this was the first that he'd heard of the work: saying that he'd recently read about it in a journal.

He goes for planes and trains at the very last minute, to the distress of ordinary folk accompanying him. Currently, he is on a Sotheby's course on Chinese Ceramics; noted in his diary as "PRCP on Course". Lesser mortals, please note. It is fortunate that his time at his College coincided with Dame Flona's time at ours: the two colleges are now working more closely together than ever, so that together they have inaugurated a new era in relationships between doctors in these two important branches of medicine.

\section{Professor Per Bech (introduced by Professor Eugene Paykel)}

Professor Per Bech is former President of the Association of European Psychiatrists. He is Europe's leading psychiatrist in the science and art of rating scales, and a long time Danish friend of British psychiatry, whose election to the Honorary Fellowship at this joint meeting is most apt, timely and well deserved.

He was born in 1942, and educated at the University of Copenhagen, where he received his medical degree in 1969. He recetved scientific training at the Psychochemistry Institute, Copenhagen, followed by clinical psychiatric training in and near Copenhagen at the Rigshospitalet, the Municipal Hospital of Copenhagen and Sct. Hans Hospital. Since 1981 he has been Head of the Department of Psychiatry, Frederiksborg General Hospital, Hillerød, where he is now Head of the Psychiatric Institute which in 1995 became a WHO Collaborating Centre for Mental Health. Since 1991 he has been Professor at Odense University.

Professor Bech's scientific work has been in the areas of rating scales, psychopharmacology, and affective disorders. In the field of rating scales he has assumed the mantle once worn by our Max Hamilton. His doctoral thesis in 1981 was on rating scales for affective disorders. He has devised and validated the well known rating scales for mania and melancholia which bear his name. I can attest from long personal experience as a journal editor that he is the most knowledgeable, fair minded and authoritative expert assessor in the world on psychiatric rating scale design, methodology and statistics. He is an active member of the Cochrane Collaboration.

Per Bech is a man of warmth, tact and courage. Many years ago an operation for a lesion of his vocal cords left him with permanent dysphonia. Other than making him a master of the microphone, it has not in any discernible way limited his capacity to lecture, chair, or make a witty speech, or for that matter, impaired his steady and continuing rise. Nor has it stopped him being a gregarious and charming social companion and friend.

He has recetved many honours and occupied many distinguished roles. He was awarded a Gold Medal from the University of Aarhus for studies of cannabis. He received the Anna Monika Prize in 1983 for studies of rating scales, and the Duphar Antidepressant Award in 1993. He has been Chairman of the Committee on Clinical Trials of the Scandinavian Society of Psychopharmacology and Chairman of the Subcommittee on Standardisation of Clinical Trials of the European College of Neuropsychopharmacology. Since 1991 he has been Chairman of the European Committee for Standardisation of Clinical Trials with Psychotropics. He is a Corresponding Member of many other European associations concerned with psychopharmacology and with psychiatry, and is a Member of the Editorial Boards of many international journals, including Psychological Medicine. He is author of more than 200 papers 
on clinical psychiatry, psychometry methods, diagnosis and classification, psychopharmacology and biological psychiatry. He has written and edited a number of books on rating scales.

From 1992 to 1994 Professor Bech was President of the Association of European Psychiatrists, during part of the time of its impressive growth into a major European force. He hosted its Congress in Copenhagen in 1994, achieving a very large meeting of such scientific and social success that the Association immediately decided to return there for its 1998 meeting.

Professor Bech's election at this meeting is a most apt symbol of our warm friendship with colleagues elsewhere in Europe and our place as a Royal College itself spanning two nations which are part of Europe. It is, however, his own personal achievements and qualities which qualify him to be honoured in this way. I have much pleasure in presenting him to the College as an Honorary Fellow.

\section{Professor John Wing (introduced by Dr Jim Birley)}

The British are famous, or even notorious, for being empiricists. The British Empire has almost disappeared but British Empiricism is alive and well. Professor John Wing is a very special empiricist indeed, based as he is on science, passion, and Swordfish.

That human beings are affected by their social environment is a truism. To scientifically explore that truism, by testing specific hypotheses and developing appropriate methodology, has been the basis of John's work. For instance over 30 years ago, he and George Brown demonstrated that the so-called 'natural' course of chronic schizophrenia was due, to a considerable degree. to the unnatural conditions provided for them by psychiatric institutions. From this there followed studies of psychiatric services, and of ways of assessing mental states. The present state examination circled the globe, for the World Health Organization's study of schizophrenia.

What about the passion? John Wing was fortunate to train at the Netherne Hospital where a passionate superintendent from Germany was demonstrating the value of a rehabilitation programme for all the patients. But an ever more important schooling, in my view, for himself and for his wife Lorna came from their autistic daughter Susie, whom they brought up in a loving home through thick and thin. This experience gave them passion, compassion, and understanding, for the psychiatrically disabled and for their relatives - and also highly discriminating antennae for assessing the true quality of a psychiatrist. The first book which a new trainee on my visit had to read was Schizophrenia at
Home by John and Clare Creer - a classic, still relevant today.

The Swordfish? This was a biplane of ancient design left over from the 1914-18 war which was still used by our Fleet Air Arm during our last war. The only biplane to be involved in battle situations, it was inclined to require a longer runway than our aircraft carriers could provide. John was a Swordfish navigator. This required skill and courage. John has both and they have both been tried in all sorts of ways during his career.

John was a member of the Medical Research Council's Social Psychiatry Unit at the Institute of Psychiatry from 1957, and its Director for 25 very distinguished and productive years. He was also a Professor at both the Institute and at the London School of Hygiene, reflecting his interest in public health and the planning and evaluation of psychiatric services. When he retired, the College was very fortunate to be able to appoint him as the first Director of our Research Unit. The Unit rapidly expanded as he assembled a team of people who have developed methodologies for the assessment of activities all highly relevant to our work. For instance of audit, quality control, and the assessment of need for services in a population. This last is the basis of the new purchaserprovider arrangement in our Health Services which, until recently, has been based rather more on guesswork and custom than on science.

I am reaching the end of my $\mathbf{5}$ minutes runway. but before dropping off, I must say two more things. The first, at John's request, is to remind everybody here that the Research Unit was launched by contributions from members of the College. It has flourished on research grants, but some more long-term money is badly needed. There is, therefore, a further appeal under way. and contributions are required, in any reasonable hard currency.

The second is to answer the question that must be in your minds. Why has the College taken so long to honour John Wing? The answer is that he has only just retired from being, as Director, an employee of the College and we never award Honorary Fellowships to employees, or Elected Officers. We may have lost our Empire, but we still have our ethics. President, I present Professor John Wing to you, as an Honorary Fellow.

\section{Response on behalf of the newly appointed Honorary Fellows}

I regard it as a privilege and a pleasure to respond this morning on behalf of we newly appointed "Honorary Fellows".

"Honorary" I think I understand. It is a distinction conferred and much appreciated. Moreover, if you have been paying a subscription 
you are excused henceforth! But the term "Fellow" is more complex and implies, among many things, a special kinship and set of responsibilities.

What your choice of "Honorary Fellows" on this occasion does seem to show, is your vision of the breadth and diversity of our subject; striving to sustain its medical identity on the one hand and yet reach out to the human interface with its social, including political, forces on the other hand. Just three of us are psychiatrists. The six of us can be expected to cover this broad spectrum of personal, social, medical, psychobiological and neurobiological dimensions to our subject.

By adopting such a breadth our College lays some claim to the relatedly diverse opportunities and tasks. For instance, how to combine the proper care of the seriously mentally ill with the ability to identify the kind of depression that is more accurately a statement about the human condition and a potential pathway to personal growth and greater maturity; how to understand more about the wider and social ramifications of avoidant, manipulative and reaction formative defences against personal and group anxiety and, for instance, their expression in the form of addiction, tyranny and violence respectively: how to grasp the true importance of helpless anger as it festers away destructively in the body?

Such clinical and social challenges as these beckon no more or less than the College's political aim for the public to adopt more constructive attitudes to mental illness, perhaps through help with development of the public's greater personal self awareness and wider social awareness of its corporate role in society's present day sicknesses.

In such tasks, along with many others, the College has a potentially robust contribution to make. I would like to think that we, your new batch of honorands, hope not only to bask in the glow of this honour bestowed upon us but also wish to continue to contribute in our various ways that will specifically befit and can benefit the College. It is in this spirit then that I dare to think we all thank you for conferring this honour upon us. Thank you from us all.

PROFESSOR CRISP 